\title{
Análise semiótica na compreensão de aspectos culturais do design
}

\author{
Semiotic analyses in the understanding of cultural aspects in design
}

\author{
CRESTO, Lindsay Jemima; Mestre; Universidade Tecnológica Federal do Paraná \\ lincresto@hotmail.com
}

\author{
QUELUZ, Marilda Lopes Pinheiro; Doutora; Universidade Tecnológica Federal do Paraná \\ pqueluz@gmail.com
}

\begin{abstract}
Resumo
Este artigo propõe uma reflexão sobre aspectos culturais do design de produtos a partir de uma análise semiótica de mobiliário. Como parte de um estudo de mestrado, a análise semiótica mostra-se como uma metodologia, um olhar que contribui na compreensão de significados amplos e múltiplos que o design comunica em sua materialidade. Para tal, tomou-se a poltrona Multidão, criada por Fernando e Humberto Campana, como ponto de partida para discutir a linguagem do design e os referenciais culturais que estabelece. A análise semiótica é apresentada como um meio de ler objetos e compreender re-significação que ocorre na interação entre design e tecnologia, design e artesanato.
\end{abstract}

Palavras Chave: Semiótica; Design e cultura; Design de produto; Irmãos Campana.

\begin{abstract}
This article proposes a reflection on cultural aspects of product design from a semiotic analysis of furniture. As part of a study to Master's semiotic analysis is shown as a methodology, a look that contributes to the understanding of large and multiple meanings that design communicates in its materiality. To this end, became the chair Crowd, created by Fernando and Humberto Campana, as a starting point for discussing the cultural references that it contains. Semiotic analysis is presented as a means of reading objects and understand the re-signification that occurs in the interaction between design and technology, design and craftsmanship.
\end{abstract}

Keywords: Semiotic; design and culture;Product desig; Campana brothers.

\section{Introdução}

A análise semiótica da poltrona Multidão tem por finalidade discutir e refletir sobre a multiculturalidade e o hibridismo, presentes na obra dos designers Fernando e Humberto Campana. Buscou-se compreender como acontecem os processos de re-significação e revalorização dos artefatos no móvel analisado, considerando a materialidade os vários processos dinâmicos de interação aí construídos. Foi possível discutir os aspectos comunicativos que o móvel apresenta, permitindo dialogar com questões mais amplas, que se mostram como discursos sobre cultura e identidade. A cultura, na concepção de Laraia (1996, p. 70), abrange "o modo de ver o mundo, as apreciações de ordem moral e valorativa, os diferentes comportamentos sociais e mesmo as posturas corporais são assim produtos de uma herança 
Análise semiótica na compreensão de aspectos culturais do design

cultural, ou seja, o resultado da operação de uma determinada cultura."

As criações dos irmãos Campana dialogam com os elementos do imaginário da cultura brasileira e, simultaneamente, com aspectos globais. Nestes diálogos, são evocadas questões relacionadas à cultura nacional, compreendida como um sistema de representação, um dispositivo que adota a diferença como representação da unidade ou da identidade. (HALL, 2006). Neste âmbito, a cultura nacional pode representar um conjunto de símbolos e imagens com os quais os indivíduos se identificam, ou que identificam como sentimento de pertencimento à nação. A cultura nacional, desta forma, funciona como fonte de significados.

O processo de identificação pode ocorrer em nível individual, quando se discutem a identidade do sujeito, e coletivo, na medida em que se pode pensar em identificação com os temas de uma cultura. Como acredita Hall $(2006$, p.76) "as identidades nacionais representam vínculos a lugares, eventos, símbolos, histórias particulares". Esta relação de pertencimento, muitas vezes, materializa-se nos artefatos produzidos na sociedade. Deste modo, os móveis, por exemplo, deixam de ser concebidos somente como produtos com funções eminentemente práticas e utilitárias, para converterem-se em meios de comunicação de valores da cultura, da identidade, do design e da tecnologia.

A Semiótica possibilita contemplar a diversidade de significados que os designers imprimem ao móvel: questiona os discursos representados por relações icônicas, uso de metáforas, símbolos e referências. Por estas razões, a semiótica de Charles S. Peirce foi adotada como um importante fundamento para direcionar a análise, associada aos modelos descritos de autores que utilizam metodologias da Semiótica e do Design para análise de produtos.

\section{Metodologia de análise}

A análise semiótica utiliza três bases para análise. A primeira é o modelo de análise de imagem proposto por Martine Joly; o segundo é a classificação que Bernd Löbach (2000) desenvolveu para as funções dos produtos industriais, que se assemelham às dimensões sintática, semântica e pragmática, consideradas na Semiótica. O terceiro modelo de análise foi baseado no trabalho de Susan Vihma (1995), que estuda os produtos a partir de suas dimensões comunicativas.

Martine Joly (1996) elaborou um roteiro de análise de imagem que pode ser aplicado aos produtos. $O$ roteiro considera os signos plásticos, icônicos e linguísticos, separados em três categorias, que correspondem às dimensões sintática, semântica e pragmática. Os signos plásticos referem-se à composição visual e seus elementos, como cor, ritmo, proporção, etc. Os signos icônicos são aqueles aspectos que estabelecem uma relação de iconicidade entre os vários componentes da imagem. Os signos linguísticos são constituídos por elementos de texto, desde a tipografia escolhida, analisando cores, formas, até os significados que as escolhas apresentam. Neste roteiro há a fragmentação dos signos de uma imagem, para só depois interpretar os significados dos signos de cada categoria, realizando um registro global dos significados da imagem, um tipo de síntese dos aspectos gerais e seus entrecruzamentos.

Já no modelo de Bernd Löbach, existe uma relação entre as funções dos produtos industriais, como o autor classifica, e as dimensões sintática, semântica e pragmática. A dimensão sintática trata das relações e associações das escolhas de elementos formais como linhas, formas, cores, texturas; a dimensão semântica trata do que o produto comunica, quais significações evoca; a dimensão pragmática está associada às relações entre produto e usuário e as possíveis significações dessa relação. 
Lindsay Jemima Cresto; Marilda Lopes Pinheiro Queluz

Para Löbach (2001, p.58), "os aspectos essenciais das relações dos usuários com os produtos industriais são as funções dos produtos, as quais se tornam perceptíveis no processo de uso e possibilitam a satisfação de certas necessidades". As funções práticas situam-se no nível fisiológico e corporal, na relação entre usuários e produtos. Esta função relaciona-se com o uso do produto e com sua capacidade em satisfazer as necessidades físicas do usuário. Uma cadeira, por exemplo, pode ter entre suas funções práticas permitir que o usuário possa mudar de posição enquanto está usando a cadeira; ou ainda prever certa postura pela forma do assento e do encosto. A função prática está ligada ao aspecto físico de uso, enquanto que a função estética influencia a "percepção dos produtos com os sentidos, principalmente a visual tátil e sonora" (LÖBACH, 2001, p. 59), sugerindo o uso do produto por meio dos sentidos.

A função simbólica, de acordo com Löbach (2001, p. 64) é "determinada por todos os aspectos espirituais, psíquicos e sociais do uso". É estimulada pela percepção dos elementos estéticos, tais como forma, cor, superfície. A relação simbólica é estabelecida por associações e ligações, baseadas nas sensações que o usuário possui. O autor ainda defende que "um símbolo é um sinal, um signo que existe para algo". As funções estética e simbólica possuem uma relação de associação e proximidade, sendo muitas vezes interdependentes.

Para Vihma (1995), a análise parte de uma coleta de informações sobre o produto a ser analisado. Este procedimento inclui buscar informações sobre a história do produto, que pode ser encontrada em diversas fontes, como museus, bibliotecas, etc; saber se o produto é ainda comercializado, como são as vendas, os fabricantes, os usuários. A percepção do produto é como um objeto tridimensional, avaliando o processo de construção, formas e funcionamento por meio de uma observação detalhada. O procedimento seguinte é separar as diferentes partes do produto, como os aspectos funcionais, ergonômicos, técnicos e a composição visual destes elementos. Vihma (1995, p. 91) divide a análise em: produto como ícone, produto como índice e produto como símbolo. $\mathrm{Na}$ análise do produto como ícone, são observados aspectos plásticos e relacionados aos processos de design (desde a cor até os materiais utilizados e metáforas pela forma). Na análise do produto como índice, são analisados aspectos formais que indicam funcionamento, fabricação, usos, sensações; na análise do produto como símbolo, são analisados como os símbolos comunicam elementos através da cor, tipologia, posicionamento, disposição, formas, etc.

A análise semiótica do mobiliário, com base nos modelos citados anteriormente, precisa considerar, ainda, que todas essas relações e associações são forjadas nas dimensões sócioculturais. Este foi o caminho escolhido para refletir sobre a linguagem dos irmãos Campana e para compreender os possíveis significados, decorrentes dos discursos dos designers, a partir da materialidade de seus produtos.

\section{Análise Semiótica da poltrona Multidão}

A cadeira Multidão foi criada entre 2001 e 2002, integrando uma série de móveis com uma linguagem baseada no acúmulo, naquilo que os irmãos Campana chamaram de uma estética "over" (MONACHESI, 2007). Algumas peças, nesta fase, aproximavam-se do kitsch, termo usado pelos próprios designers. Na concepção dos designers, o kitsch está associado ao acúmulo de objetos, às referências decorativas, aos objetos agrupados. Segundo Moles (1994, p. 64)

ao lado do objeto Kitsch intrínseco, cujo valor parece estar bastante ligado a uma função de gratuidade essencial, de decoração - cuja formação diz respeito ao campo

Projética Revista Científica de Design I Universidade Estadual de Londrina I V.2 I N.2 I Dezembro 2011 
Análise semiótica na compreensão de aspectos culturais do design

artístico -, e que opera também enquanto portador de signo, deve-se atribuir um espírito Kitsch a um grande número de objetos que têm por função primária um papel técnico, mas também, de maneira secundária, desempenham funções de portadores de signo.

O móvel é feito com bonecas de pano, que servem de assento e também de encosto da cadeira. $O$ aço inoxidável está presente na estrutura e nos pés, servindo como suporte ao móvel e é quase invisível quando comparada à composição do assento. Deste modo, o metal apresenta uma clareza visual e limpeza, com pouquíssima interferência na composição cromática da poltrona. As bonecas, feitas de tecidos variados, possuem componentes como fitas, laços, cordões, papéis, miçangas e outros detalhes que complementam a caracterização de cada uma delas.

Quanto aos aspectos formais, a sensação tátil na poltrona é a sensação do toque do tecido (liso ou com texturas), das costuras, dos enfeites. A sensação é de uma superfície suave, insinuando o conforto, como se as bonecas fossem realmente almofadas.

As cores estão presentes nas diferentes roupas e acessórios das bonecas, numa composição harmônica, sugerindo um aspecto dinâmico e alegre. A variedade de cores e estampas de tecidos pode ter como possível significado a multiplicidade de etnias ou raças que formam o país, lembrando o interior do Brasil e, ao mesmo tempo, a multiplicidade das grandes metrópoles. Esta interpretação torna-se mais plausível quando comparada à explicação dada pelo site dos designers, sobre a origem da cadeira: "os irmãos Campana foram até tradicional fábrica nordestina e trouxeram as bonecas para São Paulo, que retratam a migração do Nordeste para o Sudeste". (site CAMPANAS, 2011). O efeito do colorido obtido pela mistura de padrões pode ser pensado como metáfora para multidão ou para espaços onde as pessoas se perdem e se confundem no coletivo, ainda que mantendo suas características individuais.

A percepção de custo da poltrona é afetada pelos aspectos simbólicos e conceituais, muito mais do que os materiais utilizados. Por um lado, os retalhos de tecidos sugerem uma matéria-prima barata. Por outro lado, a noção do valor no móvel é dada pelo trabalho artesanal complexo que é feito na cadeira: representado pelas bonecas feitas pela comunidade; e pelo trabalho dos designers em produzir um móvel com as bonecas.

As linhas e formas predominantes são as linhas inclinadas dos pés, e as linhas inclinadas das bonecas e bonecos. A curvatura é dada pela composição do assento. O aspecto geral é de irregularidade, confusão, instabilidade. Esta sensação é reforçada por algumas bonecas, posicionadas com as pernas para cima, não sendo possível ver a cabeça. A sensação de caos e movimento desordenado é uma característica resultante destes elementos visuais que se cruzam e se sobrepõem.

A dinâmica também é indicada pela disposição das bonecas e a maneira como foram fixadas ao assento, com pés e braços apontando para várias direções, reforçando a multiplicidade de informações sinestésicas.

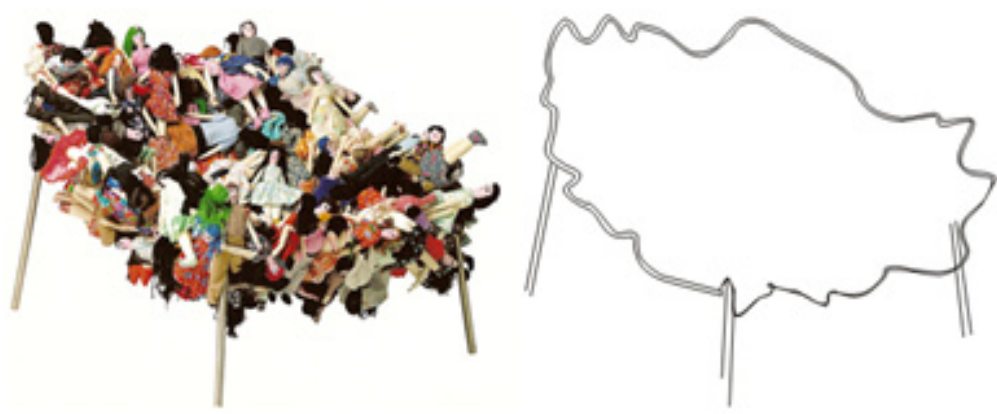

Figura 1- A poltrona Multidão e as linhas formadas pelo contorno da poltrona 
Lindsay Jemima Cresto; Marilda Lopes Pinheiro Queluz

Fonte: Arc Design (2003). Arquivo da autora.

Obs: é possível observar as linhas verticais finas e discretas em comparação com a irregularidade do assento. À direita, o detalhe das bonecas posicionadas de maneira desordenada.

O deslocamento do uso das bonecas, de objetos e brinquedos para o assento do móvel, pode despertar sentimentos de surpresa, ironia, humor, estranhamento. Há certa subversão em colocar bonecas - semelhantes às pessoas - em uma poltrona, pois há um desvio da função (prática, de uso) prevista inicialmente para uma poltrona - sentar. Ressaltam-se outras funções, como a simbólica. Cria-se o efeito de sentar sobre a multidão, gerando ambigüidades de sentidos. $O$ ato de sentar reveste-se de várias possibilidades figurativas: o/a usuário/a torna-se mais um/a na multidão? Prensar a multidão seria indiferença às pessoas? Os signos presentes no móvel instigam questionamentos: quem são essas pessoas representadas na cadeira? Como se sentar sobre a multidão? Sentar sobre as bonecas pode ser compreendido como uma forma de opressão? Jogar-se, soltar-se na poltrona é ser acolhido/a por ela? Neste sentido, o assento seria um convite para este abraço coletivo, para um jogo coletivo, do qual passamos a fazer parte no ato do uso? A proposta de brincadeira com as formas, funções e materiais, é instaurada na configuração e na linguagem deste produto.

Considerando-se o contexto de fabricação, as bonecas são feitas por artesãs da comunidade da localidade de Esperança, em uma região rural do interior da Paraíba. As artesãs confeccionam bonecas para aumentar a renda familiar, pois os homens geralmente trabalham nas roças e chegam a receber $R \$ 5,00$ por dia de trabalho. (ACASA.ORG, 2011). O processo de fabricação das bonecas ilustra como acontece a escolha de vestuário, cores, tipos, penteados; estes nascem do repertório individual de cada artesã. As artesãs ainda se divertem com o fato de que algumas bonecas lembram pessoas conhecidas: "tem boneca que a gente faz e acha tão engraçada, que parece com uma pessoa que a gente conhece." (AGÊNCIA CLICK, 2007).

Os tecidos e outros materiais são doados à comunidade; gerando um resultado tão variado, como nas roupas e acessórios. A criação destas bonecas segue alguns passos que permitem que elas tenham algumas características comuns, embora existam diferenças que resultam da criatividade e da percepção individual das artesãs como a artesã Maria do Socorro, que aprendeu a fazer suas bonecas com a tia aos sete anos de idade e acredita que confeccionando as bonecas pode "fazer alguém feliz" (AGÊNCIA CLICK, 2007).

O processo de confecção destes artefatos é descrito por M. Góes, que ouviu as artesãs paraibanas explicarem um processo que parece simples, mas que envolve uma complexidade de referências.

O processo de trabalho da confecção começa sempre pelas pernas. Depois de separar vários retalhos, a artesã corta-os e os enrola em forma de cone. Em seguida faz os sapatos, de tecido colorido ou preto, às vezes amarrados com um pequeno cordão. O corpo é o próximo passo - um retângulo recheado com retalhos e fios picados em que se modela a cintura. [...] Segue-se a modelagem dos dedos, das mãos e dos braços, estes em forma semelhante à das pernas, embora mais finos. Depois é a vez da cabeça: com forma triangular e tonalidade rosa, recebe, bordados, os olhos, a boca e as sobrancelhas; acrescentando-se o volume do nariz, a boneca está pronta para receber o cabelo, de malha desfiada, cordão, lã ou fios coloridos. Tecidos lisos - azuis, vermelhos, amarelos -, de xadrez, listras, de bolinhas ou floridos, miçangas, fitas e muita imaginação: começa a modelagem da roupa e acessórios. Vestidos, blusas, saias, gravatas... De material reciclado, aparecem jóias e relógios... um pedacinho de papel alumínio transforma-se em pulseira, uma continha, uma miçanga, em brincos. Esmalte nas unhas é lei. (GOES, 2000, p.20). 
Os vestidos de estampas floridas e coloridas estão associados aos tecidos populares. $O$ colorido dos vários tecidos das roupas das bonecas, quando visualizados no conjunto, remete à chita, ao colorido, à riqueza visual dos elementos que compõem as estampas. O tecido conhecido como chita, que atualmente é considerado item da moda, tradicionalmente esteve ligado à ideia de simplicidade, associado às classes menos abastadas. A chita recentemente integrou as sandálias havaianas, numa releitura do uso popular, transformando-se um item de moda.

As roupas das bonecas lembram elementos do folclore regional, das festas juninas, das tradições interioranas sintetizadas pela na construção visual do caipira, nas danças nordestinas, nas festas populares e quadrilhas que possuem um vestuário caracterizado pelo uso de cores variadas e estampas múltiplas.

As diferenças entre o feminino e o masculino são representadas através das roupas, como o vestido, símbolo da indumentária feminina. É interessante notar que a roupa masculina é geralmente caracterizada pela combinação calça e camisa. O corte de cabelo é outro elemento que funciona como ícone e índice do gênero: o cabelo comprido diferencia homens e mulheres; os penteados e longos cabelos presos distinguem as mulheres. O penteado de tranças é um tipo de índice curioso como forma de identificar posturas e locais, remetendo a origem do campo ou regional. A trança pode ter ainda a conotação de ingenuidade, simplicidade, pois é freqüentemente associado às meninas e jovens. Os homens são identificados pelos cabelos curtos e barba.
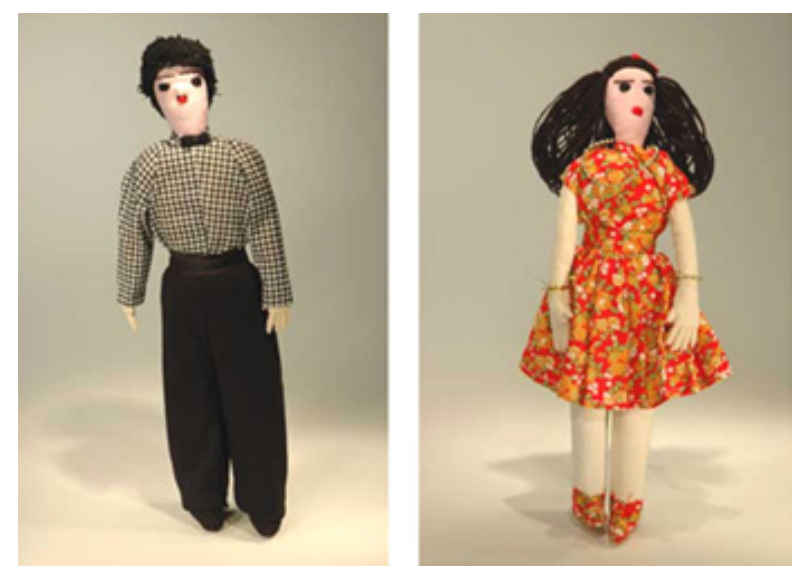

Figura 2- A diversidade com que se apresentam as bonecas Fonte: Acasa.org (2011)

Obs: mostrando diferenças no vestuário, cabelos, etc. A representação do masculino também possui aspectos múltiplos, como a tipologia do vestuário.

Neste sentido, a percepção de valor da cadeira está relacionada à aplicação das bonecas; uma perspectiva de valorização devido ao trabalho de confecção artesanal. Outra perspectiva é a valorização do conceito do móvel: os elementos reunidos no móvel, e que inspiraram sua criação/construção. A noção de valor da cadeira começa com o trabalho das artesãs e sua habilidade em imprimir detalhes nas bonecas, quase como personagens; e continua com a transposição destes artefatos para um móvel, sob a reinterpretação dos irmãos Campana. 0 próprio roteiro de criação das bonecas, apresentado anteriormente, contribui para estabelecer o valor. Embora muitas pessoas desconheçam este processo, quando observam atentamente a cadeira, percebem um tipo de trabalho mais complexo; o gesto que modifica os materiais, 
Lindsay Jemima Cresto; Marilda Lopes Pinheiro Queluz

transformando-os em artefatos complexos. Uma peça de mobiliário, um objeto de design, um artefato artesanal, brinquedos, objetos lúdicos, decorativos e emocionais se sobrepõem em camadas de memória. Os significados se multiplicam e a percepção de valor aumenta de acordo com o repertório simbólico percebido e experimentado no móvel.

O usuário provável do móvel seria alguém que se interessa pelas manifestações da arte popular e pelos elementos que falam de arte regional. Podem ser considerados como público idealizado, pessoas que buscam elementos que oferecem um diferencial de exclusividade, como o artesanato considerado "tradicional" de algumas regiões ou comunidades, que acreditam que estes artefatos são "feitos à mão". E que procuram referências da identidade local, pela associação com pessoas reais que a boneca permite. Estes elementos de identificação, sejam de origem ou lugar, estão presentes no consumo de artefatos artesanais.

A inspiração da poltrona nasceu da observação da realidade da migração de um grande contingente de pessoas do nordeste rumo ao sudeste, neste caso, com destino a São Paulo: é uma multidão que vivencia as vantagens e problemas das metrópoles, como a maior oferta de empregos, como a superlotação dos transportes públicos, o trânsito caótico, o constante deslocamento de pessoas que percorrem, apressadas, as ruas da cidade. Este ir e vir, este deslocamento e redistribuição no espaço urbano parece estar materializado na poltrona, transformando-se também num discurso poético que se destaca na linguagem do produto. A "Multidão" está relacionada à arte popular, aos elementos regionais, ao artesanato e às expressões do Nordeste brasileiro. Mas também indica aspectos do tumulto da vida nas grandes cidades, misturando gentes, hábitos e costumes.

Este conjunto de bonecas, cores, roupas e tipos diferentes pode ser compreendido como composição plástica e formal, na qual está representado o grande centro urbano do país, espaços de entrecruzamentos de informações: formações, crenças, gostos, aparências. $\mathrm{Na}$ Cadeira Multidão, encontram-se elementos associados à complexidade da vida nas sociedades contemporâneas: são muitos (multidão, mestiços, regiões, origens), são partes ou unidades (pessoas, indivíduo, boneca) que formam o coletivo (comunidade, multidão, sociedade, cidade, país). É possível pensar num diálogo sobre o regional e o nacional, sobre aquilo que nos distancia e aquilo que nos aproxima das outras pessoas na percepção do coletivo, entre a indeterminação e a identidade; a heterogeneidade e a massificação.

As numerosas bonecas que personificam atributos humanos, permitem a construção do imaginário da multidão, situada na cidade. As bonecas, da maneira como foram usadas no móvel (assento e encosto), provocam reflexões sobre os modos de uso da cadeira; criam uma relação de cumplicidade entre a multidão que se projeta do assento e a pessoas que podem sentar.

No caso da cadeira Multidão, o fazer artesanal está imbricado ao projeto dos irmãos Campana, borrando as fronteiras do próprio conceito de design. A fabricação da cadeira contribui, mesmo que de modo indireto, com a mudança da situação econômica, social e cultural das artesãs. $\mathrm{O}$ artesanato da comunidade é promovido em circuitos que elas não atingiriam de outro modo, fazendo com que públicos distantes e tão diferentes possam conhecer a atividade e as bonecas de Esperança. O trabalho dessas artesãs é promovido e valorizado quando a cadeira adquire visibilidade, como valor de representação de sua atividade. Ruth Cardoso comenta o papel de Fernando e Humberto Campana no reconhecimento do trabalho da comunidade Esperança:

Tinha uma senhora que fazia na perfeição estas bonequinhas tradicionais no sertão. Esta junção entre a arte dos irmãos campana e a utilização dos recursos da arte popular, mostra realmente que nós temos raízes, as raízes estão aqui nestas 
Análise semiótica na compreensão de aspectos culturais do design bonequinhas e que nós temos uma maneira muito avançada, muito contemporânea de olhar para o nosso país e de produzir arte. Então para mim esta cadeira é o objeto que simboliza esta integração. Eles produzem a mudança quando eles são reconhecidos. (AGÊNCIA CLICK, 2007).

Neste contexto, seria interessante discutir este processo de criação como um processo de co-autoria, embora esta co-autoria não esteja explícita nos discursos dos irmãos ou nas informações referentes à cadeira. A poltrona Multidão é uma conversa com a confecção artesanal das bonecas, com o trabalho das várias artesãs da comunidade, amarrando o traço/ fazer de cada uma delas ao traço/fazer dos designers.

A inserção da cadeira em exposições, museus, feiras, comercializada em todo o país e em outros países, estimula a reflexão sobre os deslocamentos e a re-significação que o móvel adquire, assim como a transformação das bonecas, que são reinterpretadas pelo imaginário individual de cada pessoa que conhece a cadeira. Uma pessoa pode conhecer a cadeira na Europa, por exemplo, sem conhecer a realidade da migração no país, mas vai rearticular os temas e os valores culturais presentes nos aspectos materiais, estéticos e simbólicos da cadeira.

A cadeira apresenta-se como uma forma de expressão, como um olhar sobre a multidão, as pessoas, as cidades e a diversidade dos contextos sócio-culturais. É um discurso sobre o deslocamento, sobre a redistribuição e a re-significação do cotidiano. A reconfiguração proposta pelos Campana instaura questionamentos na relação design e artesanato, design e tecnologia, deslocando a questão da função para os usos e as apropriações simbólicas. Mais do que classificar ou imprimir julgamentos ao produto, ou fornecer chaves interpretativas, o que esta análise evidencia é a importância de se situar o design como cultura material e de se discutir os significados e conceitos produzidos pela atividade de projetar.

\section{Referências}

A CASA. Museu do objeto brasileiro. Disponível em:<http://www.acasa.org.br/>. Acesso em: 28 ago. 2010.

AGÊNCIA CLICK. Cadeira Multidão. Vídeo. Duração: 03:45. Brasil, 2007. Disponível em:<http:// br.youtube.com/results?search_query=irm\%C3\%A3os+campana\&search_type=\&aq=f>. Acesso em: 30 ago. 2010.

CAMPANA, Fernando; CAMPANA, Humberto. Campanas. São Paulo: Bookmark, 2003.

CAMPANAS. Site oficial dos irmãos Campana. Disponível em: <http://www.campanas.com.br>. Acesso em: abr. 2011.

GOES, M. Brinquedos do Agreste Paraibano. A Casa, 2000. Disponível em:<http://www.acasa. org.br/arquivo_biblio.php?id=372\&modo=bibliografia>. Acesso em: 15 ago. 2010.

HALL, Stuart. A identidade cultural na pós-modernidade. Rio de Janeiro: DP\&A, 2006.

JOLY, Martine. Introdução à análise de imagem. Campinas: Papirus, 1996.

LARAIA, Roque de Barros. Cultura. Um conceito antropológico. 11. ed. Rio de Janeiro: Jorge Zahar Editor, 1996. 
Lindsay Jemima Cresto; Marilda Lopes Pinheiro Queluz

LÖBACH, Bernd. Design Industrial: bases para a configuração dos produtos industriais. São Paulo: Edgard Blücher, 2001.

MOLES, Abraham. O kitsch: a arte da felicidade. 4. ed. São Paulo: Perspectiva, 1994.

MONACHESI, J. Entrevista Fernando e Humberto Campana. Folha de São Paulo, 28 jul. 2007. llustrada. Disponivel em:<http: //www1.folha.uol.com.br/folha/ilustrada/ ult90u312713. shtml>. Acesso em: set. 2010.

VIHMA, Susan. Products as representations: a semiotic and aesthetic study of design products. Helsinki: University of Art and Design Helsinki UIAH, 1995. 